\section{Protein crystallography}

\section{Fifty years of pepsin crystals}

\section{from Guy Dodson and Cyrus Chothia}

IN the middle of April 1934, J.D. Bernal and Dorothy Crowfoot (now Hodgkin) obtained the first successful X-ray photographs of a globular protein. They were obtained in Cambridge from crystals of pepsin grown by John Philpot in Uppsala. The photographs, discussed in a letter to Nature $(133,794 ; 1934)$ published half a century ago, almost to the day, were the start of one of the great achievements of modern biology.

On 13 April 1984 a meeting was held in Cambridge to commemorate the fiftieth anniversary of the experiment. Lectures were given by Dorothy Hodgkin, Max Perutz and Aaron Klug, all of whom worked at different times in Bernal's laboratory. The occasion brought together all those still living who were directly involved in the pepsin experiment; sadly, Peter Wooster, a long-established figure in Bernal's laboratory and remembered warmly by many, died on the night preceding the meeting. Several crystallographers who had contributed to the field, notably Arthur Wilson (intensity statistics) and Henry Lipson (Fourier calculation methods), were also present.

Part of the meeting was devoted to a recreation of the events that led to the pepsin crystal's coming to Bernal's laboratory at Camtridge and to the crystallographic examination of pepsin and other protein crystals (including viruses) that subsequently took place. The historical accounts were filled out, sometimes straightened out, particularly by John Philpot on the background of the crystallization of pepsin (in explaining why he went to Uppsala to grow the crystals he distinguished nicely between his real reason for going there - a young lady - and his excuse - to work on the ultracentrifuge) and by Bill Pirie on early virus experiments. The history of pepsin was completed by a comment from Tom Blundell on the structure of the pepsin molecule inferred from homologous enzymes.

The impressions that emerged of Bernal's laboratory were of great activity and many abilities, and of Bernal's omnivorous scientific interests. The laboratory already had a famous reputation, particularly for the work on sterols, and it was this, or Dorothy Crowfoot's reputation, that apparently prompted Glen Millikan, a peripatetic scientist, to bring John Philpot's crystals to Cambridge.

When the crystals arrived, Bernal immediately examined them in a polarizing microscope (Dorothy Crowfoot was away with what proved to be an incipient rheumatic attack). He found them to be beautifully formed, showing sharp birefringence while in the tube they had been grown in.
The crystals failed to diffract after removal from the test tube and drying but, crucially, Bernal noticed that their birefringence had also disappeared. Thus he realized the need to keep crystals wet. Bernal's solution was to put the crystals in capillaries (made possible because of Helen Megaw's studies on ice crystals). The subsequent investigation of the crystal's diffraction characteristics, cell dimensions and space group was carried out by Bernal and Dorothy Crowfoot. It led to their recognition "that the arrangement of atoms inside the protein molecule is of a perfectly definite kind" and to remarkably accurate ideas about the molecules' molecular weight and shape.

The descriptions of the subsequent research into protein crystals included the details of how the studies on insulin, haemoglobin and the viruses began. The immense difficulties in solving these structures were clearly appreciated at the time and the early investigations were devoted to measuring $\mathrm{X}$-ray intensities, to calculating the Patterson function (also celebrating its fiftieth anniversary this year) and to characterizing new protein crystals. The influence of Bernal and Bragg was clearly crucial. A typical contribution was Bernal's letter to Dorothy Crowfoot suggesting that the isomorphous replacement of $\mathrm{Zn}$ by $\mathrm{Cd}$ in the rhombohedral insulin crystal could give phase information. Bragg's role, more concentrated at first on haemoglobin and later on myoglobin, was quieter but his steady sympathy, persistence and deep crystallographic insight helped the early research called Bragg's grasp of crystallographic principles and illustrated it by the studies on how the shrinkage of protein crystal cells could be used to define centric phases.

In his review of virus research and the structure of water, both deep interests of through disappointing years. Perutz re-

Bernal, Klug emphasized the importance of flexible thinking and how Bernal's aphorism, 'crystallographers must learn not to be crystallographers', applied over and over again. This was as true in Pauling's production of the $\alpha$-helix structure and in Bernal's approach to the water problem as it is now in the study of the behaviour of protein structure which is increasingly found to link well defined domains to flexible and variable segments. Thus, the linking of order and disorder to achieve assembly and function (RNA binding) in the tobacco mosaic virus is revealed by crystallographic analysis. A report by Steven Harrison (Harvard University) of the $2.8 \AA$ resolution crystal structure of tomato bushy stunt virus nicely completed studies begun by Bernal and Fankuchen. This virus also demonstrates beautifully the order-disorder phenomenon, which Harrison showed is related to the packing and assembly of the virus subunits.

There are many conclusions from a day like this. First, there are the remarkably happy collaborative traditions in protein crystallography, established from the earliest days, that make it such fun to work in the field. Second, the techniques, essentially physics, have put the description of protein and biomolecular structure into the hands of crystallographers. Finally, the importance of crystals and other ordered systems as a route to the description of biochemical and biological structure remains paramount. Bernal saw these descriptions as the first stage - their analysis should lead to the principles which govern the assembly and integration of molecules into higher organizations. Already, as Richard Henderson emphasized, crystals of very large molecular assemblies such as the nucleosome have been solved. Thus, as long as there are crystals, the future of the field is assured and more than justifies the great excitement produced by those first X-ray photographs of pepsin.

Guy Dodson is in the Department of Chemistry, University of York, York YO1 5DD, and Cyrus Chothia is at the Medical Research Council, Laboratory of Molecular Biology, Cambridge $C B 22 Q H$, and the Department of Chemistry, University College of London.

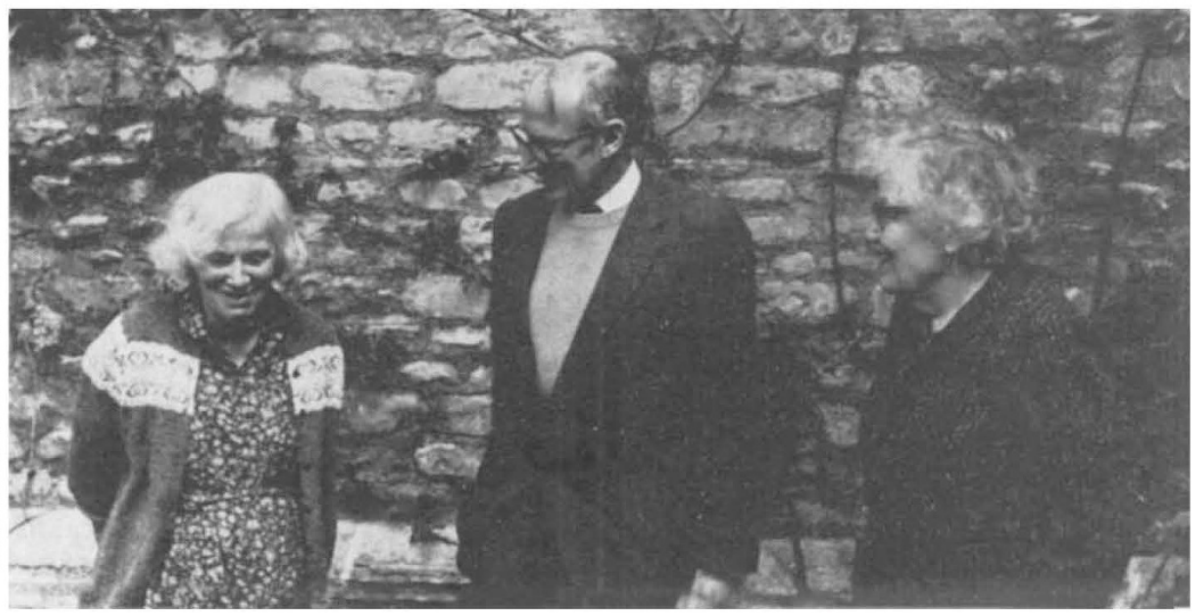

Dorothy Hodgkin, John Philpot and Helen Megaw at the meeting. (Photograph by Claudio Villa.) 